\title{
Cenários Sustentáveis para a Macrometrópole Paulista
}

\author{
Sustainable Scenarios to the Macrometropolis Paulista
}

\author{
Antonio Carlos Demanboro ${ }^{1}$ \\ Braulio Fabiano ${ }^{2}$ \\ Regina Márcia Longo ${ }^{3}$ \\ Sueli do Carmo Bettine 4
}

\section{Resumo}

A Macrometrópole Paulista (MMP) compreende três Regiões Metropolitanas do Estado de São Paulo: a Região Metropolitana de São Paulo (RMSP), a Região Metropolitana de Campinas (RMC) e a Região Metropolitana da Baixada Santista (RMBS), além de suas áreas de influência. Abriga cerca de 30 milhões de habitantes e é uma das áreas mais críticas em termos de demanda e disponibilidade de recursos hídricos. O Objetivo é propor cenários alternativos, que visem o planejamento ambiental integrado das bacias que compõem a MMP, a saber: Alto Tietê; Piracicaba, Capivari e Jundiaí; Sorocaba e Paraíba do Sul. A metodologia utilizada baseou-se no modelo Pressão-Estado-Resposta proposto pela OECD (1993; 2003), com base na seleção de indicadores, considerando a relevância política, utilidade aos usuários, confiabilidade e mensurabilidade de cada indicador. Para a execução do diagnóstico ambiental foram selecionados os indicadores demanda, disponibilidade, área florestada, qualidade da água e índice de perdas na distribuição, permitindo a representação das bacias e subsidiando a elaboração dos cenários. Os cenários elaborados (Tendencial, Desenvolvimento Sustentável e Conservação) simularam a evolução dos indicadores em diferentes situações, propondo medidas de priorização de investimentos e de gestão dos recursos hídricos. Dessa forma, foi possível propor ações que busquem garantir a sustentabilidade das bacias que compõem a MMP.

Palavras-chave: Macrometrópole Paulista. Sustentabilidade. Gestão Ambiental.

\begin{abstract}
The Macrometropole Paulista (MMP) comprises three Metropolitan Regions of the State of São Paulo: the Metropolitan Region of São Paulo (RMSP), the Metropolitan Region of Campinas (RMC) and the Metropolitan Region of the Baixada Santista (RMBS). It is home to some
\end{abstract}

\footnotetext{
1 Pontifícia Universidade Católica de Campinas, Campinas, São Paulo, Brasil. demanboro@puccampinas.edu.br

2 Pontifícia Universidade Católica de Campinas, Campinas, São Paulo, Brasil. bfabiano@puccampinas.edu.br

3 Pontifícia Universidade Católica de Campinas, Campinas, São Paulo, Brasil. Regina.longo@puccampinas.edu.br

4 Pontifícia Universidade Católica de Campinas, Campinas, São Paulo, Brasil. subettine@puccampinas.edu.br

Artigo recebido em: 08/06/2018. Aceito para publicação em: 18/02/2019.
} 
30 million people and is one of the most critical areas in terms of demand and availability of water resources. The objective is to propose alternative scenarios, aiming at the integrated environmental planning of the basins that make up the MMP, namely: Alto Tietê; Piracicaba, Capivari and Jundiaí; Sorocaba and Paraíba do Sul. The methodology used was based on the Pressure-State-Response model proposed by the OECD (1993; 2003), based on the selection of indicators, considering the political relevance, utility to users, reliability and measurability of each indicator. In order to carry out the environmental diagnosis, the indicators demand, availability, forested area, water quality and loss index in the distribution were selected, allowing the representation of the basins and subsidizing the elaboration of the scenarios. The scenarios elaborated (Trend, Sustainable Development and Conservation) simulated the evolution of the indicators in different situations, proposing measures of prioritization of investments and management of water resources. In this way, it was possible to propose actions that seek to guarantee the sustainability of the basins that make up the MMP.

Keywords: macrometropolis Paulista, sustainability, environmental management.

\section{Introdução}

A Macrometrópole Paulista (MMP) é a região do estado de São Paulo que abriga a maior mancha urbana do país e a terceira maior do planeta. A MMP possui uma área de 53,4 mil $\mathrm{km}^{2}$ que corresponde a $21,5 \%$ da área do Estado de São Paulo. Abriga uma população de 33,6 milhões de habitantes, em 2018, que representa $74,7 \%$ da população do Estado, sendo responsável por $81,9 \%$ do PIB estadual, em 2016. É composta por 174 municípios, que perfazem um percentual de $50 \%$ da área urbanizada do estado, sendo que do ponto de vista ambiental é responsável por $20 \%$ do patrimônio natural protegido do Estado (EMPLASA, 2017).

Nela, estão inseridas as regiões metropolitanas de São Paulo, Campinas, Baixada Santista, Vale do Paraíba, Litoral Norte e Sorocaba, bem como as aglomerações urbanas de Jundiaí e Piracicaba, com a unidade de Bragantina prestes a ser inserida (EMPLASA, 2014).

Seu elevado nível econômico também traz desafios, tanto sociais como ambientais, principalmente nos setores de infraestrutura, mobilidade e logística, habitação e saneamento ambiental. 
Dessa forma, faz-se necessário uma análise de sua atual condição, além da implementação de políticas públicas, que devem ser feitas de forma holística, tal como é o seu território (EMPLASA, 2014).

Neste sentido, o objetivo deste artigo é propor cenários que visem o planejamento ambiental integrado das bacias que compõem a MMP, através da realização do diagnóstico físico e ambiental das bacias; da seleção de indicadores ambientais relevantes no cenário atual (Tendencial) e; do desenvolvimento de cenários alternativos para a situação dos recursos naturais, denominados Cenário Desenvolvimento Sustentável e Cenário Conservação, analisando os aspectos de demanda e disponibilidade hídricas, qualidade da água, controle de perdas hídricas e áreas florestadas.

\section{O Planejamento Ambiental, os Indicadores e a Elaboração de Cenários Ambientais}

No planejamento ambiental, é a escala temporal que norteia a análise do espaço estudado, bem como a criação de modelos futuros de situação, indicando as mudanças ocorridas durantes o tempo analisado. Assim, é possível notar os tipos de modificações e identificar os causadores, podendo ser observado tanto em um meio natural como nos modificados pela ação do homem, o que favorece o processo de tomada de decisão (SANTOS, 2004).

Ainda segundo Santos (2004), a representação temporal é realizada através da construção de cenários, os quais contextualizam a paisagem em determinados momentos da escala de tempo, o que fornece aos planejadores um melhor entendimento das ações exercidas sobre a área e os impactos ambientais resultantes. Assim, os tomadores de decisão podem modelar com maior eficiência a relação espaço, tempo e meio, possuindo um olhar mais fiel sobre as fragilidades da área analisada.

Para Sánchez (2008) são as ideias opostas, a base da elaboração de cenários, além da variação de ações de planejamento ou suas ausências, 
restrições e limitações, bem como condições para preservação do ambiente e melhoria na qualidade de vida da população.

\section{A Macrometrópole Paulista (MMP)}

A MMP (Figura 1) compreende a área do principal polo produtivo e densidade urbana do País. Localiza-se na MMP três Regiões Metropolitanas do Estado de São Paulo: a Região Metropolitana de São Paulo (RMSP), a Região Metropolitana de Campinas (RMC) e a Região Metropolitana da Baixada Santista (RMBS), bem como suas áreas de influência (EMPLASA, 2017).

Figura 1 - Perímetro da macrometrópole Paulista.

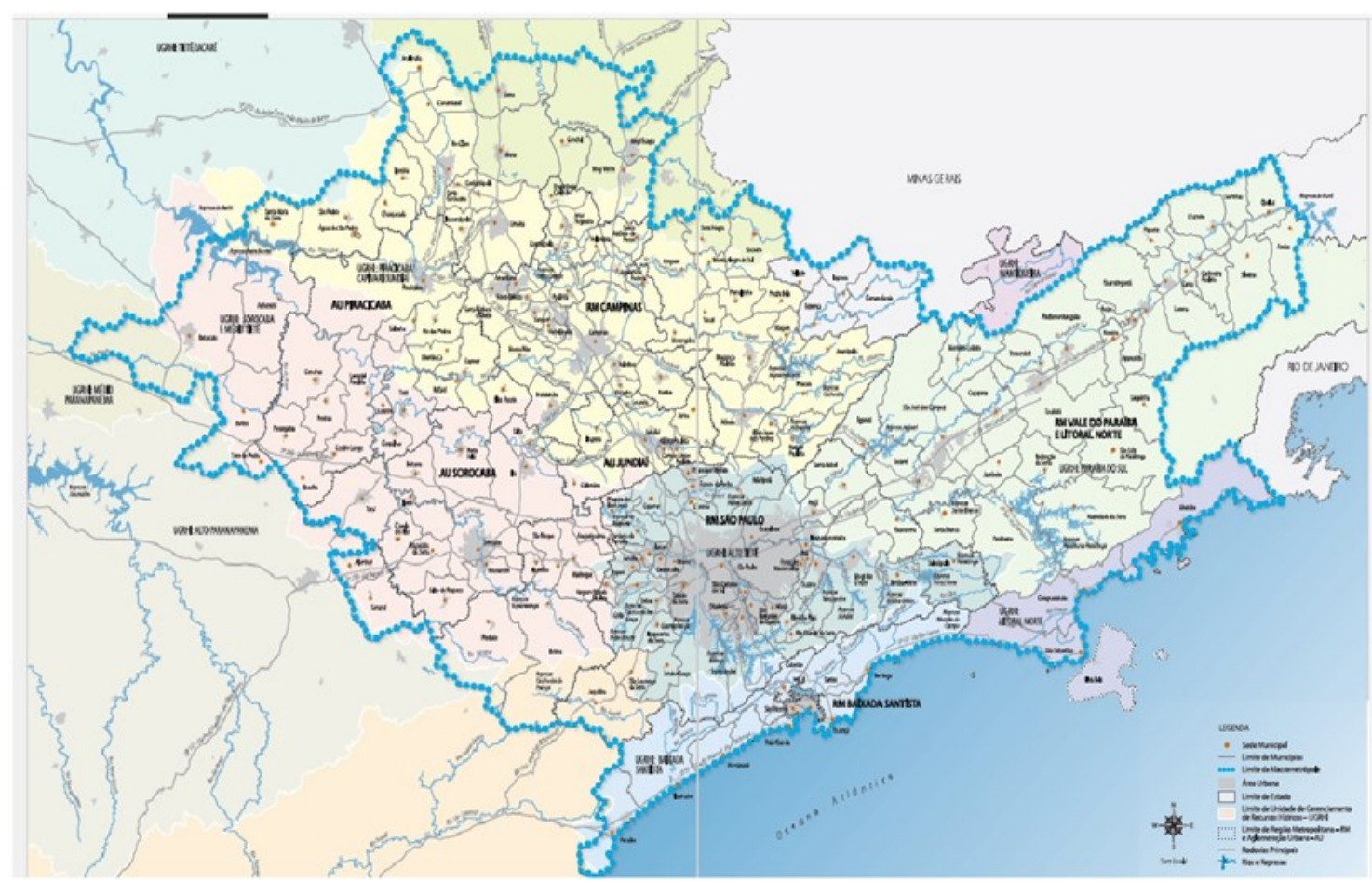

Fonte: DAEE, 2013.

Fazem parte ainda das regiões metropolitanas, os municípios localizados na UGRHI 05 (Piracicaba, Capivari e Jundiaí), considerando os munícipios pertencentes ao Estado de Minas Gerais; os munícipios 
integrantes da UGRHI 10 (Sorocaba e Médio Tietê); municípios paulistas localizados na UGRHI 02 (Paraíba do Sul). Os municípios do Litoral Norte também fazem parte da MMP, por possuírem elevada atividade turística, além de seu potencial crescimento econômico, devido às melhorias que estão sendo realizadas e projetos futuros, principalmente os relacionados à infraestrutura ao porto de São Sebastião (COBRAPE, 2013).

A MMP é a principal concentração urbana nacional, possuindo uma estrutura de produção complexa e bem diversificada, sendo caracterizada por sua estrutura heterogênea. Sua rede urbana é diferenciada em relação ao porte populacional, configuração e perfil funcional, visto se tratar de uma região que possui um intenso fluxo na troca de consumo de bens e serviços, somado a relação pendular moradia-trabalho (RQA, 2015).

Vê-se a grande importância da região ao notar-se que a mesma abriga, atualmente, mais de 30 milhões de habitantes, o que representa $75 \%$ da população paulista, além de ser responsável por mais de $80 \%$ do PIB estadual (RQA, 2015).

\section{Economia}

A RMSP se destaca por ter uma elevada produção industrial, mas com a presença maior do setor terciário, bem como maior concentração de atividades financeiras, estando diretamente ligada com a economia mundial (COBRAPE, 2013).

Uso e Ocupação do Solo e Cobertura Vegetal

A figura 2 apresenta o mapa de uso e ocupação do solo na MMP. 
Figura 2 - Uso e ocupação do solo na MMP.

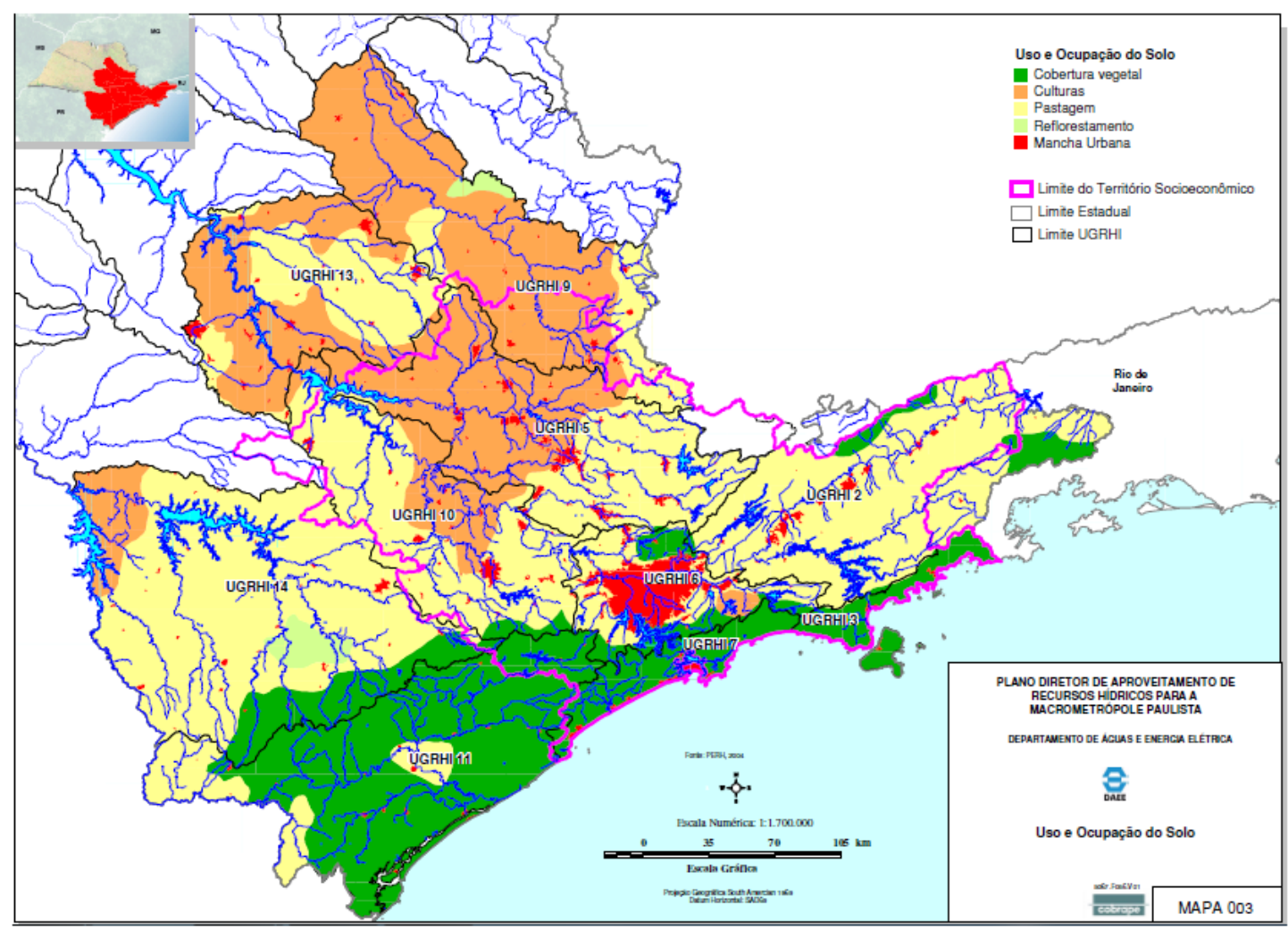

Fonte: Cobrape, 2013.

Com relação a Reserva Legal, são necessários no mínimo $20 \%$ de cobertura vegetal no Estado, porcentagem muito superior em algumas UGHRI's, porém distante na maioria das Unidades inseridas na MMP, como mostrado na tabela 1 . As maiores quantidades de cobertura vegetal estão no litoral do Estado que, somados, representam $60 \%$ da vegetação remanescente (SigRH, 2015). Assim, nota-se não apenas a pouca área com vegetação nativa restante, mas também que sua localização é heterogênea, com um cenário interiorano oposto ao visualizado no litoral, fato evidenciado pelos grandes déficits nas UGRHI's.

Grandes áreas necessitam ser revegetadas para se atingir a meta mínima, medida que é de caráter de longo prazo e de alto valor de investimento, porém essencial para a recuperação das bacias hidrográficas. 
Tabela 1 - Área Total e de Cobertura vegetal de cada URGHI inserida na MMP.

\begin{tabular}{|c|c|c|c|c|c|}
\hline UGRHI & $\begin{array}{l}\text { Área } \\
\left(\mathrm{km}^{2}\right)\end{array}$ & $\begin{array}{c}\text { Cobertura } \\
\text { Vegetal }\left(\mathrm{km}^{2}\right) \\
\end{array}$ & $\begin{array}{c}\text { Cobertura Vegetal } \\
\text { Mínima }\left(\mathrm{km}^{2}\right) \\
\end{array}$ & $\begin{array}{l}\text { Déficit } \\
\left(\mathrm{km}^{2}\right)\end{array}$ & $\begin{array}{c}\text { Superávit } \\
\left(\mathrm{km}^{2}\right)\end{array}$ \\
\hline 02 - Paraíba do Sul & 14444 & 1271 & 2888,8 & $-1617,8$ & - \\
\hline 03 - Litoral Norte & 1948 & 1899 & 389,6 & - & 1509,4 \\
\hline $05-$ PCJ & 14178 & 1911 & 2835,6 & $-924,6$ & - \\
\hline 06 - Alto Tietê & 5868 & 1397 & 1173,6 & - & 223,4 \\
\hline 07 - Baixada Santista & 2818 & 2669 & 563,6 & - & 2105,4 \\
\hline 09 - Mogi Guaçu & 15004 & 1598 & 3000,8 & $-1402,8$ & - \\
\hline $\begin{array}{c}10 \text { - Tietê/Sorocaba } \\
11 \text { - Ribeira do }\end{array}$ & 11829 & 2104 & 2365,8 & $-261,8$ & - \\
\hline Iguape/Litoral Sul & 17068 & 14388 & 3413,6 & - & 10974,4 \\
\hline 13 - Tietê/Jacaré & 11779 & 1106 & 2355,8 & $-1249,8$ & - \\
\hline 14 - Alto Paranapanema & 22689 & 2995 & 4537,8 & $-1542,8$ & - \\
\hline TOTAL & 117625 & 31338 & 23525 & $-6999,6$ & 14812,6 \\
\hline
\end{tabular}

Fonte: SigRH (2015), adaptado pelo autor.

Grandes áreas necessitam ser revegetadas para se atingir a meta mínima, medida que é de caráter de longo prazo e de alto valor de investimento, porém essencial para a recuperação das bacias hidrográficas.

Dessa forma, a ausência de cobertura vegetal é uma das causas da degradação das bacias hidrográficas do estado de São Paulo, visto que impacta diretamente na qualidade e quantidade de água disponível na MMP.

\section{Abastecimento de Água e Esgotamento Sanitário}

Os índices de atendimento de água, bem como os de coleta e tratamento de esgotos na MMP, foram baseados nos dados referentes do Sistema Nacional de Informações sobre o Saneamento (SNIS, 2007), além de dados obtidos da SABESP (2008), ou ainda, dados obtidos pelos Planos de Bacias Hidrográficas, sendo adaptados pois consideravam apenas a população urbana (COBRAPE, 2013).

A tabela 2 indica o Índice de Atendimento médio por serviços de Água e Esgoto em cada UGRHI, a partir dos dados disponibilizados. Nota-se que 
em toda a MMP, o abastecimento de água e tampouco a coleta de esgotos são realizados em sua totalidade, o que evidencia a precariedade deste serviço.

Tabela 2 - Índices de Atendimento médio por serviços de Água e Esgoto, por UGRHI.

\begin{tabular}{ccccc}
\hline & & & \multicolumn{2}{c}{$\begin{array}{c}\text { Índice de Tratamento de Esgotos } \\
\text { (\%) }\end{array}$} \\
\cline { 3 - 5 } UGRHI & $\begin{array}{c}\text { Índice de atendimento total } \\
\text { de água (\%) }\end{array}$ & $\begin{array}{c}\text { Índice de Coleta de } \\
\text { Esgotos (\%) }\end{array}$ & $\begin{array}{c}\text { (Sobre o esgoto } \\
\text { coletado) }\end{array}$ & $\begin{array}{c}\text { (Sobre o esgoto } \\
\text { gerado) }\end{array}$ \\
\hline 02 & 79,0 & 73,6 & 42,7 & 34,9 \\
03 & 94,0 & 39,3 & 100,0 & 39,3 \\
05 & 84,0 & 71,0 & 36,6 & 29,5 \\
06 & 88,3 & 55,3 & 32,1 & 19,0 \\
07 & 91,9 & 41,8 & 95,4 & 40,4 \\
09 & 89,6 & 81,9 & 30,2 & 25,7 \\
10 & 76,7 & 72,4 & 57,0 & 41,8 \\
11 & 38,2 & 17,0 & 100,0 & 17,0 \\
\hline MÉDIA & 80,2 & 56,5 & 61,8 & 31,0 \\
\hline
\end{tabular}

Fonte: Cobrape (2013), adaptado pelos autores.

\section{Estudos Envolvendo as Disponibilidades Futuras na MMP}

O planejamento hídrico da MMP tem sido feito, ao longo dos anos, via contratação de estudos visando o aumento da disponibilidade de água. De acordo com DAEE (2015), vários estudos foram elaborados visando ampliar as disponibilidades na MMP, a saber:

a) Estudos de viabilidade foram elaborados para o reforço da vazão da MMP através das represas Itapanhaú e Itatinga, totalizando $5,65 \mathrm{~m}^{3} / \mathrm{s}$ a serem disponibilizados em Biritiba e Jundiaí.

b) A represa de Jurumirim poderia contribuir com 6 a $8 \mathrm{~m}^{3} / \mathrm{s}$ e o Aquífero Guarani com $5 \mathrm{~m}^{3} / \mathrm{s}$ para a RMC.

c) A reversão das águas da Bacia do Médio Tietê disponibilizaria $30 \mathrm{~m} / 3 / \mathrm{s}$ para Guarapiranga e Cantareira.

Deste modo, haveria possibilidade de aumento da disponibilidade entre 46,65 e $48,65 \mathrm{~m}^{3} / \mathrm{s}$, isto sem se considerar os elevados custos envolvidos (DAEE, 2015). 


\section{Balanço hídrico}

Apresenta-se a seguir, o balanço hídrico, que é a diferença entre a disponibilidade e a demanda na MMP, com base nos dados e informações disponíveis nos relatórios elaborados por CEIVAP (2013) e COBRAPE (2013). Isto se faz necessário, uma vez que as ações previstas pelo DAEE para aumentar a disponibilidade na MMP, apresentadas no item anterior, não foram realizadas.

A Tabela 3 indica as disponibilidades e demandas hídricas atuais, bem como o balanço hídrico.

Tabela 3 - Balanço hídrico para as principais UGRHI's da MMP.

\begin{tabular}{cccc}
\hline \multicolumn{4}{c}{ Balanço hídrico para as principais UGRHI's da MMP } \\
\hline UGRHI & Demanda $\left(\mathrm{m}^{3} / \mathrm{s}\right)$ & Disponibilidade $\left(\mathrm{m}^{3} / \mathrm{s}\right)$ & Balanço $\left(\mathrm{m}^{3} / \mathrm{s}\right)$ \\
\hline 2 - Paraíba do Sul & 305,4 & 311,9 & 6,5 \\
5 - PCJ & 37,0 & 38,0 & 1,0 \\
6 - Alto Tietê & 111,1 & 77,0 & $-34,1$ \\
10 - Sorocaba & 31,5 & 39,0 & 7,5 \\
\hline TOTAL & 485,0 & 465,9 & $-19,1$ \\
\hline
\end{tabular}

Fonte: CEIVAP (2013); Cobrape (2013), adaptado pelo autor.

Todas as UGRHI's avaliadas estão em situação crítica de disponibilidade e, por isso, é necessário destacar alguns pontos sobre o balanço hídrico apresentado na tabela 3. A UGRHI 05 tem apenas $1 \mathrm{~m}^{3} / \mathrm{s} \mathrm{de}$ 'folga', mas desde que se considere as vazões a serem adicionadas pelas barragens Duas Pontes e Pedreira, que apenas em 2018 tiveram iniciada sua construção (DAEE, 2019) A UGRHI Alto Tietê é, de longe, a que apresenta pior situação, com déficit de $34,1 \mathrm{~m}^{3} / \mathrm{s}$, o que acarretará na necessidade de trazer água de locais cada vez mais distantes, visando a tender a demanda da RMSP, como mostrado neste artigo, no item que tratou das disponibilidades futuras. No caso da Bacia Paraíba do Sul, destaca-se a grande reversão de água para o Sistema Guandu (até $160 \mathrm{~m}^{3} / \mathrm{s}$ ), utilizada para o abastecimento da região Fluminense, além do grande volume 
utilizado para a diluição de esgoto, devido à falta de tratamento. Além disso, em épocas críticas, a vazão do Rio Paraíba do Sul diminui acentuadamente, o que potencializa o problema. Na Bacia do Médio Tietê/Sorocaba, o elevado consumo de água ocorre devido à sua utilização para a agropecuária, sendo tal setor responsável por mais da metade (56\%) do consumo da Bacia, o que ameaça a oferta do recurso para os outros setores, conforme citado por COBRAPE (2013).

\section{Controle de perdas}

Uma rede de distribuição sem perdas não é algo que possui viabilidade técnica e econômica, mas deve haver um limite para a diminuição dos volumes perdidos (ABES, 2013).

No caso da RMSP, os dados divergem de acordo com a fonte. No Relatório de Administração da SABESP (2015), o índice de perdas em 2013 era de 31,2\%; em outras ocasiões, afirmou-se que o índice era de apenas 25\%. Entretanto, para o município de São Paulo, no ano de 2013, o índice era de 35,8\%. Se somados os índices de perdas na distribuição dos municípios mais populosos da RMSP, o índice médio de perdas chegou a $41 \%$, de acordo com os dados disponibilizados pelo Sistema Nacional de Informações sobre Saneamento (SNIS), indicados na tabela 4.

Tabela 4 - Municípios populosos da RMSP e índices de perdas na distribuição de água.

\begin{tabular}{ccc}
\hline Municípios & População (hab) & Índice de perdas na distribuição (\%) \\
\hline Carapicuíba & 387788 & 32,86 \\
Diadema & 406718 & 44,04 \\
Guarulhos & 1299249 & 35,00 \\
Itaquaquecetuba & 344558 & 51,44 \\
Mauá & 444136 & 48,22 \\
Mogi das Cruzes & 414907 & 56,42 \\
Osasco & 691652 & 51,51 \\
Santo André & 704942 & 23,74 \\
São Bernardo do Campo & 805895 & 41,92 \\
São Paulo & 11823871 & 35,79 \\
Suzano & 279520 & 36,13 \\
Taboão da Serra & 264352 & 34,93 \\
TOTAL & 17867588 & - \\
MÉDIA & - & 41,00 \\
\hline
\end{tabular}

Fonte: SNIS, 2013, adaptado pelos autores, 2016. 


\title{
Metodologia
}

Os dados e informações utilizados nas seções anteriores deste artigo foram coletados em extensa pesquisa bibliográfica realizada pelos autores. Salienta-se que a leitura e interpretação dos dados e informações contida nos relatórios contratados pelo DAEE foi uma tarefa árdua, uma vez que muitas delas apresentavam-se em contraposição entre si.

Quanto aos cenários elaborados, estes foram construídos pelos autores, com base nas informações disponíveis para a elaboração do cenário Tendencial, bem como em projeções e avaliações feitas pelos autores para elaboração dos Cenários Desenvolvimento Sustentável e Conservação. Utilizou-se como horizonte de planejamento o ano de 2035.

A metodologia utilizada baseou-se no modelo Pressão x Estado x Resposta, proposto pela OCDE (2003). Para a OCDE (2003), as atividades humanas realizam pressões, tanto diretas como indiretas sobre o ambiente, causando impactos quantitativos e qualitativos no ambiente (estado).

A resposta ocorre através da sociedade, que se mostra atenta a tais impactos e realiza intervenções via políticas ambientais, setoriais e econômicas, buscando mitigar os impactos.

Neste sentido, Tayra e Ribeiro (2006) afirmam que:

\begin{abstract}
De maneira geral, o modelo busca descrever a dinâmica de um problema ambiental; por exemplo, a pressão ambiental decorrente da deposição de esgotos em um rio ou a diminuição de área disponível para a vida selvagem. Tais pressões alteram o estado do sistema ambiental, reduzindo a qualidade da água ou a diversidade de espécies. Tais alterações, por seu turno, conduzem, em alguns casos, a respostas dos governos, ou das instituições (entre os quais, o próprio mercado).
\end{abstract}

Os indicadores ambientais são essenciais para os processos de tomada de decisão, uma vez que fornecem uma visualização dos dados do diagnóstico, além de ferramentas para a construção de cenários, podendo 
realizar a análise das condições do meio e observar as consequências da decisão tomada. Além disso, propicia analisar as mudanças ocorridas no ambiente, o que permite ao planejador a capacidade de realizar medidas preventivas baseadas nos cenários futuros e nas ações consideradas primordiais estabelecidas pelos objetivos do planejamento (LAURENTIS, 2008).

Assim, segundo OCDE (2003):

\begin{abstract}
Os indicadores ambientais da OCDE são regularmente utilizados nos exames dos desempenhos ambientais; eles constituem uma valiosa ferramenta no acompanhamento da integração das decisões econômicas e ambientais, na análise das políticas de meio ambiente e na avaliação dos resultados. Mas sua utilidade ultrapassa o simples campo dos exames dos desempenhos ambientais da OCDE: eles contribuem igualmente para o objetivo mais amplo de relatar fatos sobre o desenvolvimento sustentável.
\end{abstract}

A quantidade de indicadores utilizados em um estudo é proporcional a escala de trabalho utilizada, além de também estar relacionado às características do local. Outro fator é a quantidade de informações disponíveis sobre o local, passíveis de interpretação, estando estes diretamente ligados ao grau de generalização do planejamento (SANTOS, 2004).

Neste sentido, foram selecionados os indicadores demanda, disponibilidade, área florestada, qualidade da água e índice de perdas, tomados para cada cenário elaborado.

\title{
Elaboração de cenários
}

Os cenários descritos a seguir foram elaborados pelos autores para a MMP, com destaque para as UGRHIs 02 (Paraíba do Sul), 05 (PCJ), 06 (Alto Tietê) e 10 (Sorocaba), devido à maior criticidade de tais bacias hidrográficas. 


\section{Cenário tendencial}

Espera-se, no ano de 2035 (horizonte utilizado para o planejamento), que a demanda de água aumente de acordo com as taxas recentes, de 1,00888\% ao ano. Dessa forma, ter-se-á uma demanda total de água de 517,05 m³ $/ \mathrm{s}$ para tais UGRHIs, como mostra a tabela 5.

Tabela 5 - Demandas e disponibilidade de água para o ano de 2035.

\begin{tabular}{lccccc}
\hline & & & Demanda & Disponibilidade \\
UGRHI & Urbano & Irrigação & Industrial & Total & Total \\
\hline 02 - Paraíba do Sul & 228,40 & 53,16 & 13,66 & 295,22 & 311,9 \\
05 - PCJ & 22,36 & 19,23 & 17,13 & 58,72 & 38,0 \\
06 - Alto Tietê & 82,84 & 4,54 & 39,56 & 126,94 & 77,0 \\
10 - Tietê/Sorocaba & 8,10 & 20,48 & 7,59 & 36,17 & 39,0 \\
TOTAL & 341,70 & 97,41 & 77,94 & 517,05 & 465,9 \\
\hline
\end{tabular}

Fonte: Autores, 2016.

Vê-se que as demandas superarão as ofertas de água nas principais UGRHI's que compõem a MMP. Destaca-se a Bacia do Alto Tietê, a qual possui demanda estimada de $126,94 \mathrm{~m}^{3} / \mathrm{s}$ e disponibilidade de apenas 77,0 $\mathrm{m}^{3} / \mathrm{s}$. Mesmo se forem somados $48,65 \mathrm{~m}^{3} / \mathrm{s}$, totalizando $125,65 \mathrm{~m}^{3} / \mathrm{s}$, que é o total possível de aumento de oferta futura, a situação do alto Tietê ainda estaria crítica.

As bacias PCJ possuem situação semelhante, pois a demanda de $58,72 \mathrm{~m}^{3} / \mathrm{s}$ é maior do que a disponibilidade futura, de $47,1 \mathrm{~m}^{3} / \mathrm{s}$.

O Tietê/Sorocaba possui balanço hídrico próximo do equilíbrio, porém crítico, com demanda de $36,17 \mathrm{~m}^{3} / \mathrm{s}$ próximo à sua disponibilidade, de $39,0 \mathrm{~m}^{3} / \mathrm{s}$.

Já a situação da bacia do rio Paraíba do Sul é bastante complexa, pois é necessário avaliá-lo no contexto de toda a bacia hidrográfica, que abrange os estados de São Paulo, Minas Gerais e Rio de Janeiro. Neste contexto, a demanda total prevista é de $295,22 \mathrm{~m}^{3} / \mathrm{s}$, para uma disponibilidade total de $311,9 \mathrm{~m}^{3} / \mathrm{s}$ na sua foz. Entretanto, tal disponibilidade corresponde a vazão regularizada (Q95) pelos reservatórios existentes ao longo do rio Paraíba do Sul e não sua vazão firme $\left(Q_{7,10}\right)$, que é mais restritiva que sua vazão firme. 
Assim, na extensão do rio Paraíba do Sul entre São Paulo e sua foz, no estado do Rio de Janeiro, há trechos em que a demanda supera a disponibilidade. Existe ainda a elevada vazão de reversão para o Sistema Guandu (205 m³/s), sendo parte do escoamento utilizado para a diluição de esgoto.

No caso da Bacia do Paraíba do Sul, mesmo o aumento de $20 \%$ no setor industrial não será o grande contribuinte para pressionar os recursos, mas sim a reversão de água para o Sistema Guandu.

$\mathrm{Na}$ Bacia do Sorocaba, a demanda total de água $\left(36,17 \mathrm{~m}^{3} / \mathrm{s}\right)$ corresponde a aproximadamente $93 \%$ da Q95. Contudo, em períodos de estiagem, a vazão disponível não supera os $22 \mathrm{~m}^{3} / \mathrm{s}$, o que evidencia a supressão do recurso, sendo este praticamente utilizado de forma plena.

Quanto ao índice de perdas na distribuição, estes permanecerão com os valores atuais, sendo em média, para a MMP, de 38\%, conforme indicado pela tabela 6 .

Tabela 6 - Índices de perda na distribuição nas principais UGRHIs na MMP.

\begin{tabular}{lc}
\hline UGRHI & IPD (\%) \\
\hline 02 - Paraíba do Sul & 39,00 \\
05 - PCJ & 32,80 \\
06 - Alto Tietê & 35,80 \\
10 - Tietê/Sorocaba & 45,00 \\
\hline MÉDIA & 38,15 \\
\hline
\end{tabular}

Fonte: SNIS, 2013, elaborado pelos autores, 2016.

Portanto, se tal índice for mantido, do total demandado $\left(517,05 \mathrm{~m}^{3} / \mathrm{s}\right)$, aproximadamente $197,3 \mathrm{~m}^{3} / \mathrm{s}$ serão perdidos entre a captação nos mananciais até ao consumidor final. A diminuição do volume de água perdido na distribuição reduziria a pressão pelos recursos existentes e a necessidade da construção de novos reservatórios e transposições de água, que além de impactos ambientais, também envolvem maiores investimentos. Gestões adequadas deverão ser realizadas em todas as bacias que compõem a MMP, visto que os recursos são escassos quando comparados com as 
demandas. Além disso, medidas em todos os setores serão necessárias para garantir o abastecimento.

Para a área urbana, não só o controle de perdas é vital, mas também o uso racional dos recursos, como a reutilização da água e aproveitamento de águas pluviais. Medidas de educação socioambiental também são válidas para a conscientização do cenário de estresse hídrico em que se encontra a Macrometrópole.

Quanto ao setor agropecuário, menores volumes de água devem ser utilizados através de tecnologias mais eficientes no uso da água, como a irrigação por gotejamento, podendo-se também aproveitar as águas pluviais. Para o setor industrial, deve-se intensificar o uso de tecnologias na produção, que visem o menor consumo de água, além de desenvolver práticas de reaproveitamento.

\section{Qualidade da água}

A qualidade da água, neste cenário, mantém a tendência atual, sem a universalização da distribuição de água (média de 80\% na MMP). Quanto ao esgoto, este ainda não possui níveis de coleta adequados (média de 57\%). Assim, não há expectativa de grandes investimentos em saneamento básico, o que leva a uma maior deterioração da qualidade da água na MMP, tal como ocorre atualmente.

\section{Áreas florestadas}

Baseado nos valores disponíveis e expostos na Revisão Bibliográfica, apesar de na totalidade a MMP possuir mais de 20\% de área florestada, não ocorre de forma homogênea, sendo necessário que cada bacia hidrográfica possua a quantidade adequada de Reserva Legal. 
No total serão necessários reflorestar $6994 \mathrm{~km}^{2}$, o que não se espera que irá ocorrer neste cenário tendencial.

\section{Cenário desenvolvimento sustentável}

Neste cenário espera-se que as demandas de água diminuam nas UGRHI's.

No caso da Bacia do Paraíba do Sul, faz-se necessário uma diminuição na demanda de água para irrigação, dando ênfase a irrigação por gotejamento. Um cadastro atualizado possibilitaria uma maior fiscalização das retiradas de água pelo setor agropecuário, a fim de diminuir as retiradas abusivas.

A diminuição das perdas no sistema de distribuição de água também é fundamental, visto que um índice de perdas reduzido para $25 \%$ resultaria em uma economia de $3,28 \mathrm{~m}^{3} / \mathrm{s}$ de água. Outra ação a ser tomada é a ampliação do sistema de coleta e tratamento de esgotos, já que a vazão do Sistema Guandu aumenta demasiadamente para que ocorra diluição. Ocorrendo melhoria na qualidade da água, a reversão do Sistema Guandu reduziria de $205 \mathrm{~m}^{3} / \mathrm{s}$ para $160 \mathrm{~m}^{3} / \mathrm{s}$. No caso das residências e locais de grande circulação de pessoas, a adoção de dispositivos poupadores de água pode trazer grandes economias de água, com redução da ordem de $40 \%$ da quantidade de água utilizada.

No Setor Industrial, o cenário pouco se alterará, já que medidas buscando um menor consumo de água já vem sendo realizadas, indicando que a demanda de água permanecerá a mesma para os próximos anos (13,66 $\left.\mathrm{m}^{3} / \mathrm{s}\right)$.

Ações semelhantes devem ser tomadas nas Bacias PCJ, uma vez que a demanda de água futura é grande, com situação similar à bacia Paraíba do Sul. No entanto, maiores ações devem ser realizadas no segmento urbano e industrial, já que a oferta de água de qualidade é cada vez menor, sendo 
também necessários altos investimentos na área de saneamento básico. A diminuição das perdas de água para $25 \%$, bem como a utilização de equipamentos economizadores de água, é essencial para a diminuição do consumo de água, tanto na área urbana como industrial.

Para a Bacia do Alto Tietê, é de suma importância a redução de água no Setor Urbano, já que é o setor responsável por mais da metade da água consumida. A meta de perdas de distribuição de $25 \%$ acarretaria em grandes economias de água, de $9 \mathrm{~m} / \mathrm{s}$. Medidas parecidas devem ser tomadas no Setor Industrial, principalmente no investimento de tecnologias que utilizem menores quantidades de água e que sejam passíveis de reuso. Para a demanda agropecuária, pouco pode ser realizado, destacando-se uma maior fiscalização para evitar a poluição de mananciais.

$\mathrm{Na}$ Bacia Hidrográfica do Sorocaba/Médio Tietê, as medidas devem ser voltadas principalmente para o setor agropecuário, uma vez que é o responsável pelo maior consumo. Alternativas para irrigação, bem como maior controle da retirada de água são imprescindíveis para a redução da demanda de água, sendo necessária sua redução para $7,9 \mathrm{~m}^{3} / \mathrm{s}$, para que a segurança hídrica da região seja garantida. No segmento urbano, por possuir perdas na distribuição ainda maiores (45\%), a redução do mesmo em $20 \%$ diminuirá consideravelmente a demanda de água urbana. O setor industrial possui o menor consumo, e espera-se que sua demanda se mantenha constante. Dessa forma, com tais reduções, a UGRHI 10 teria sua demanda total próxima à vazão $\mathrm{Q}_{7,10}$, de $22,0 \mathrm{~m}^{3} / \mathrm{s}$.

A tabela 7 indica as demandas de água para 2035, se tais medidas de redução forem tomadas.

Tabela 7 - Demandas de água para o ano de 2035 - Cenário Des. Sustentável.

\begin{tabular}{lcccc}
\hline UGRHI & Urbano & Irrigação & Industrial & Soma \\
\hline 02 - Paraíba do Sul & 180,12 & 31,90 & 13,66 & 225,68 \\
05 - PCJ & 20,62 & 11,54 & 17,13 & 49,29 \\
06 - Alto Tietê & 73,89 & 2,72 & 39,56 & 116,17 \\
10 - Tietê/Sorocaba & 6,48 & 12,29 & 7,59 & 26,36 \\
\hline TOTAL & 281,11 & 58,45 & 77,94 & 417,50 \\
\hline
\end{tabular}

Fonte: Autores, 2016. 


\section{Qualidade da água}

Esperam-se maiores investimentos na área de Saneamento Básico, o que levará a melhores índices de qualidade das águas, uma vez que o esgoto é o maior contribuinte em todas as UGRHIs para a deterioração da qualidade dos recursos hídricos.

Estima-se que serão necessários investimentos pelas empresas de saneamento da ordem de 691 milhões de reais anuais pelos próximos 19 anos, para que o serviço de esgotamento sanitário seja universalizado na MMP.

\section{Áreas florestadas}

É esperado que a cobertura vegetal na MMP atinja os $20 \%$ requisitados pela Reserva Legal em todas as suas Unidades de Gerenciamento de Recursos Hídricos. Destaca-se uma maior recuperação de vegetação natural nas bacias PCJ e Paraíba do Sul, que possuem elevado déficit de Cobertura Vegetal (925 e 1618 km², respectivamente). Além disso, deve-se garantir a cobertura vegetal dos reservatórios que abastecem toda a MMP, bem como investir na criação de corredores ecológicos, para que os fragmentos ainda remanescentes sejam conectados.

Além da grande área com déficit vegetal, há a questão econômica, já que o custo para tal recuperação é elevado (estimado em $\mathrm{R} \$ 10835,00$ por hectare), totalizando $\mathrm{R} \$ 7,6$ bilhões de reais, o que dificulta sua realização (SANT'ANNA, 2015).

Entretanto, a alteração no Código Florestal ameaça a tendência de preservação das UC's, pois a lei passou a prever proteção apenas das áreas cuja declividade é superior a $25^{\circ}$ e 100 metros de altura, diferentemente da anterior, que previa a proteção para áreas de $17^{\circ}$ e 50 metros de altura. Assim, é de suma importância um maior monitoramento e manutenção das 
Unidades de Conservação, uma vez que serão essenciais para a garantia da proteção dos remanescentes florestais.

\section{Cenário conservação}

No Cenário Conservação, é esperado uma redução ainda maior nas demandas de água nas UGRHI's, com a intensificação das ações nas bacias constituintes da Macrometrópole Paulista.

Para a Bacia do Paraíba do Sul, a rizicultura terá que ser substituída por outras culturas que demandam menor quantidade de água, o que diminuiria consideravelmente o consumo de água na Bacia. Além disso, espera-se que todas as retiradas de água pelo setor agropecuário sejam devidamente cadastradas e fiscalizadas, havendo um controle integral da quantidade de água utilizada, evitando abusos.

Para o Setor Urbano, as perdas na distribuição também serão fortemente reduzidas, atingindo os níveis de países desenvolvidos, de $15 \%$. Isso levaria a uma diminuição de $5,62 \mathrm{~m}^{3} / \mathrm{s}$ na demanda de água. Para o Sistema Guandu, a melhoria na qualidade da água via tratamento de esgotos diminuiria a reversão para o Sistema, que somado à utilização racional do recurso, totalizaria em $110 \mathrm{~m}^{3} / \mathrm{s}$. Dispositivos economizadores de água terão de ser utilizados em larga escala para que os objetivos sejam atingidos.

Assim como no Cenário Desenvolvimento Sustentável, a demanda industrial não deve sofrer alterações, mantendo-se em 13,66 $\mathrm{m}^{3} / \mathrm{s}$ até o ano de 2035 .

No caso das Bacias PCJ, um melhor controle de perdas na distribuição resultaria em uma economia no setor urbano de aproximadamente $19 \%$ na demanda de água, podendo ser potencializado com medidas racionais de consumo. A diminuição do consumo por irrigação, também elevada nesta UGRHI, se faz necessária, uma vez que o nível de 
estresse hídrico é elevado nesta bacia. Além disso, possui um grande parque industrial, com elevado consumo de água atualmente e com perspectivas baixas de redução nos próximos anos, sendo responsável pelo consumo de um terço da água demandada.

Em situação mais crítica, a Bacia do Alto Tietê teria sua demanda para abastecimento urbano restringida em mais de $17 \mathrm{~m}^{3} / \mathrm{s}$, caso ocorra um rigoroso controle de perdas. Quanto à demanda agropecuária, possui a menor da MMP, não implicando em grandes economias. Já para sua indústria, o esforço será essencial para que as demandas se mantenham para os próximos 20 anos.

Já a Bacia da UGRHI Tietê/Sorocaba deve priorizar a diminuição da demanda para irrigação, uma vez que é o setor com maior demanda de água (55\%). Dessa forma, ao diminuir o consumo através de melhores tecnologias, bem como realizar um programa adequado de controle de perdas e medidas socioeducativas, sua demanda total ter-se-ia uma redução de $35 \%$, assim como a pressão sobre os recursos hídricos.

A tabela 8 indica as demandas de água para 2035 caso as ações mencionadas fossem realizadas.

Tabela 8 - Demandas de água - Cenário Conservação.

\begin{tabular}{lcccc}
\hline UGRHI & Urbano & Irrigação & Industrial & Soma \\
02 - Paraíba do Sul & 127,78 & 26,58 & 13,66 & 168,02 \\
05 - PCJ & 18,38 & 9,62 & 17,13 & 45,13 \\
06 - Alto Tietê & 65,61 & 2,27 & 39,56 & 107,44 \\
10 - Tietê/Sorocaba & 5,67 & 10,24 & 7,59 & 23,50 \\
\hline TOTAL & 217,44 & 48,71 & 77,94 & 344,09 \\
\hline
\end{tabular}

Fonte: Autores, 2016.

\section{Qualidade da água}

Assim como no Cenário Desenvolvimento Sustentável, espera-se maiores investimentos em Saneamento Básico, universalizando os serviços 
de distribuição de água potável, bem como a coleta e tratamento de esgotos em todas as UGRHIs da Macrometrópole Paulista.

\section{Áreas florestadas}

Espera-se que a cobertura vegetal na MMP seja recuperada em 50\% nas Bacias deficitárias, bem superior ao requisitado pela Reserva Legal. Assim, destaca-se uma área vegetal mais de duas vezes superior à da mínima requisitada pela Reserva Legal, com maior recuperação das Bacias Paraíba do Sul e PCJ, respectivamente. Os custos, contudo, também seriam elevados, sendo necessário reflorestar $16477 \mathrm{~km}^{2}$, o que totalizaria aproximadamente $\mathrm{R} \$ 18$ bilhões, adotando-se o valor de $\mathrm{R} \$ 10835,00$ por hectare.

A tabela 9 indica os valores a serem recuperados caso a taxa de reflorestamento seja de 50\%, comparando os valores de cobertura vegetais existentes e os valores mínimos exigidos pela Reserva Legal.

Tabela 9 - Valores das áreas recuperadas com taxa de reflorestamento de 50\% das principais UGRHI's da MMP.

\begin{tabular}{lccccc}
\hline \multicolumn{1}{c}{ UGRHI } & $\begin{array}{c}\text { Área } \\
\left(\mathrm{km}^{2}\right)\end{array}$ & $\begin{array}{c}\text { Cobertura } \\
\text { Vegetal }\left(\mathrm{km}^{2}\right)\end{array}$ & $\begin{array}{c}\text { Cobertura } \\
\text { Vegetal } \\
\text { Mínima }\left(\mathrm{km}^{2}\right)\end{array}$ & $\begin{array}{c}\text { Cobertura } \\
\text { Vegetal } \\
\text { recuperada } \\
\left(\mathrm{km}^{2}\right)\end{array}$ & $\begin{array}{c}\text { Superávit } \\
\left(\mathrm{km}^{2}\right)\end{array}$ \\
\hline 02 - Paraíba do Sul & 14444 & 1271 & 2889 & 7222 & 5951 \\
05 - PCJ & 14178 & 1911 & 2836 & 7089 & 5178 \\
06 - Alto Tietê & 5868 & 1397 & 1174 & 2934 & 1537 \\
10 - Tietê/Sorocaba & 11829 & 2104 & 2366 & 5915 & 3811 \\
\hline TOTAL & 46319 & 6683 & 9264 & 23160 & 16477 \\
\hline
\end{tabular}

Fonte: Autores, 2016.

A tabela 10 indica os investimentos necessários para a preservação dos recursos hídricos (universalizar a coleta e tratamento de esgoto), bem como os valores a serem aplicados para a recuperação das áreas verdes, de acordo com cada cenário. 
Tabela 10 - Custos para a melhoria da qualidade ambiental na Macrometrópole Paulista, em bilhões de reais.

\begin{tabular}{lccc}
\hline \multicolumn{1}{c}{ Cenário } & $\begin{array}{c}\text { Saneamento } \\
\text { básico }\end{array}$ & Áreas Florestadas & Total \\
\hline Desenvolvimento Sustentável & 13 & 7,6 & 20,6 \\
Conservação & 13 & 18 & 31,0 \\
\hline
\end{tabular}

Fonte: Autores, 2016.

Nota-se que em ambos os cenários, os custos para a melhoria do Saneamento Básico são os mesmos, pois é imprescindível sua universalização, essencial para a melhoria da qualidade dos recursos hídricos. Já para as áreas florestadas, os investimentos são proporcionais à área recuperada. Apesar dos altos valores a serem investidos, os benefícios de tais recuperações seriam inúmeros, não só ambientais, mas também sociais.

\section{Considerações finais}

Este artigo propôs ações efetivas para que se possa alcançar a sustentabilidade hídrica na MMP. Os indicadores utilizados permitiram uma avaliação das questões ambientais em sua totalidade, não se pretendo apenas ao aspecto do aumento da disponibilidade hídrica, que tem sido a ênfase dos estudos contratados pelo DAEE.

Os cenários elaborados, com base na metodologia pressão $\mathrm{x}$ estado $\mathrm{x}$ resposta, permitiram mostrar que é possível, desejável e altamente necessário diminuir as perdas de água na MMP, bem como implantar um amplo reflorestamento visando a produção de água. Além disso, permitiram mostrar que é fundamental investir em tratamento de esgotos visando melhorar a qualidade das águas, antes de se construírem barragens que serão poluídas pelos esgotos lançados. Não menos importante, também, são as medidas de gestão da demanda apotadas por este trabalho.

Nota-se que no Cenário Tendencial há uma alarmante demanda total de $517,05 \mathrm{~m}^{3} / \mathrm{s}$, muito superior à disponibilidade hídrica máxima possível, de 
$465,9 \mathrm{~m}^{3} / \mathrm{s}$, o que mostra claramente que outras ações são necessárias além do aumento da disponibilidade.

Assim, conclui-se que a MMP possui diversos problemas ambientais, sendo um grande desafio solucioná-los nos próximos anos. Tais problemas afetam diretamente as demandas e disponibilidades de águas existentes, expondo os conflitos entres os setores que demandam pelo recurso, bem como os Estados que os gerem.

É primordial que a vegetação nativa seja recuperada, buscando garantir os 20\% previstos pela Reserva Legal, tendo as Bacias PCJ e Paraíba do Sul os maiores desafios de tal recuperação, uma vez que possuem déficits de vegetação elevados e sua presença é essencial não só pelo aumento da qualidade da água, mas também sua quantidade. Um maior monitoramento das Unidades de Conservação também se faz necessário, erradicando-se completamente as devastações. O novo Código Florestal, contudo, acaba sendo mais um obstáculo para a concretização desses objetivos.

Quanto à qualidade da água, em toda a MMP devem ser realizados investimentos em saneamento básico, uma vez que o despejo de esgotos é um problema crônico constatado em todas as bacias que compõem a MMP. Destaque para a Bacia do Paraíba do Sul, que utiliza grande volume de água para a diluição de esgoto e para a Bacia do Alto Tietê, onde a maior parte da população está concentrada e com índices baixos de coleta e tratamento de efluentes urbanos.

Em relação às quantidades demandadas, é preciso reduzir a quantidade utilizada de água, através de medidas socioambientais que tornem o uso da água racional. A utilização de tecnologias economizadoras de água possui função importante na economia de água, o que indica a necessidade de sua utilização em larga escala. Já as empresas de saneamento devem agir de forma mais intensa na redução de perdas na 
distribuição, pois os valores constatados na MMP são alarmantes e acabam realizando pressão ainda maior sobre os recursos hídricos.

A confiabilidade dos dados dificulta uma análise precisa da realidade das bacias da Macrometrópole Paulista. Muitos dados estão defasados e discrepantes de acordo com a fonte consultada. Portanto, faz-se necessário um maior esforço dos Comitês de Bacia em quantificar de forma mais precisa as demandas e disponibilidades de água, bem como as empresas de saneamento atualizarem o volume de água perdido na distribuição.

Por fim, faz-se necessário que órgãos do Estado e da Federação, como a ANA (Agência Nacional de Águas) atuem de forma mais ativa nas bacias hidrográficas que formam a MMP, buscando garantir uma gestão eficiente não só dos recursos naturais, mas também levando em consideração os aspectos econômicos envolvidos.

\section{Referências}

ABES (Associação Brasileira de Engenharia Sanitária e Ambiental). Perdas em Sistemas de Abastecimento de Água: Diagnóstico, Potencial de ganhos com a sua redução e propostas de medidas para o efetivo combate. ABES, Rio de Janeiro, 2013. Disponível em: <http://abes-sp.org.br/arquivos/perdas.pdf>. Acesso em: 17/06/2016.

CEIVAP. Plano de Recursos Hídricos Consolidado - Resumo - Relatório Contratual R10 - PSR-012-R1, COPPETEC, Rio de Janeiro, dezembro de 2007. Disponível em: $<$ www.ceivap.org.br>. Acesso em: 08/04/2016.

COBRAPE (Companhia Brasileira de Projetos e Empreendimentos). Relatório Final Volume I. Plano Diretor de Aproveitamento de Recursos Hídricos para a Macrometrópole Paulista, no Estado de São Paulo. São Paulo, Outubro de 2013.

DAEE - Departamento de Águas e Energia Elétrica. As UGRHIs no contexto das Regiões/Bacias Hidrográficas do Estado de São Paulo. Disponível em: <http://www.daee.sp.gov.br/acervoepesquisa/perh2204_2207/perh08.pdf> Acesso em 15/06/2015.

DAEE - Departamento de Águas e Energia Elétrica. Página das Barragens Pedreira e Duas Pontes. Disponível em: http://www.daee.sp.gov.br/index.php?option=com content\&id=1289:audiencia-publica-dasobras-das-barragens-de-pedreira-e-duas-pontes. Acesso em 15/02/19.

EMPLASA (Empresa Paulista de Planejamento Metropolitano S/A). Macrometrópole Paulista. Disponível em: www. emplasa.sp.gov.br/MMP. Acesso em 15/02/19.

EMPLASA (Empresa Paulista de Planejamento Metropolitano S/A). Plano de Ação da Macrometrópole Paulista 2013-2040: política de desenvolvimento da macrometrópole. Secretaria da Casa Civil, Volume 1. São Paulo: EMPLASA, 2014.

LAURENTIS, G. L. Elaboração de Cenários Como Suporte ao Planejamento Ambiental da Bacia Hidrográfica do rio Atibaia. 2008. 114f. Trabalho de Conclusão de 
Curso (Graduação em Engenharia Ambiental). Faculdade de Engenharia Ambiental Pontifícia Universidade Católica de Campinas. Campinas, São Paulo, dezembro de 2008.

OCDE (Organização para Cooperação e Desenvolvimento Econômico) - OECD (Organization for Economic Co-Operation and Development). OECD Environmental indicators Development, measurement and use. Paris, 2003.

SÁNCHEZ, L. H. Avaliação de Impacto Ambiental - conceitos e métodos. São Paulo: Oficina de Textos, 2008.

SANT'ANNA, L. Sob ameaça, Cantareira precisa de 30 milhões de árvores, ao custo de R\$ 195 mi. Jornal Estado de São Paulo. Disponível em: <http://saopaulo.estadao.com.br/noticias/geral,sob-ameaca-cantareira-precisa-de-30-milhoes-dearvores-ao-custo-de-r-195-mi,1637582>. Acesso em: 30/08/2016.

SANTOS, R. F. Planejamento Ambiental: teoria e prática. São Paulo: Oficina de Textos, 2004.

SÃO PAULO, GOVERNO DO ESTADO. Plano Diretor de Aproveitamento de Recursos Hídricos para a Macrometrópole Paulista. Secretaria de Saneamento de Recursos Hídricos. São Paulo, Outubro de 2013.

SigRH. Sistema Integrado de Gerenciamento de Recursos Hídricos do Estado de São Paulo. São Paulo, 2015.

SISTEMA NACIONAL DE INFORMAÇÕES SOBRE SANEAMENTO (SNIS). Diagóstico dos Serviços de Água e Esgotos - 2013. Disponível em: < http://www.snis.gov.br/diagnostico-agua-e-esgotos/diagnostico-ae-2013>. Acesso em: $15 / 06 / 2016$.

TAIRA, F. e RIBEIRO H. Modelos de Indicadores de Sustentabilidade:síntese e avaliação crítica das principais experiências. Saúde e Sociedade v.15, n.1, p.84-95, jan-abr 2006. https://doi.org/10.1590/S0104-12902006000100009 